\title{
Making decisions for oneself and others: How regulatory focus influences the 'decision maker role effect' for intertemporal choices
}

\author{
Dawei Wang $^{\mathrm{a}, 1}$, Leilei Hao ${ }^{\mathrm{b}, 1}$, Mengmeng Zhou ${ }^{\mathrm{a}, 1}$, Phil Maguire ${ }^{\mathrm{c}}$, Xinyong Zhang ${ }^{\mathrm{d}, *}$, \\ Xiao Zhang ${ }^{\mathrm{a}, *}$, Yixin $\mathrm{Hu}^{\mathrm{a}, *}$, Xiang $\mathrm{Su}^{\mathrm{a}}$ \\ ${ }^{a}$ School of Psychology, Shandong Normal University, China \\ ${ }^{\mathrm{b}}$ School of Psychology and Cognitive Science, East China Normal University, China \\ ${ }^{\mathrm{c}}$ Department of Computer Science, National University of Ireland, Ireland \\ ${ }^{\mathrm{d}}$ Department of Applied Psychology, Guangdong University of Foreign Studies, No. 2 North Baiyun Avenue, Guangzhou, Guangdong 510420, China
}

\section{A R T I C L E I N F O}

\section{Keywords:}

Regulatory focus type

Self-other differences

Decision maker role effect

Intertemporal choice

\begin{abstract}
A B S T R A C T
We examined self-other differences in an intertemporal choice context, investigating whether choices vary according to different types of regulatory focus. In Study 1, the role of chronic regulatory focus on self-other intertemporal choice was investigated. In Study 2, we designed a causal chain of studies (Study 2a and 2b) to further examine the role of situational regulatory focus in the context of self-other intertemporal choice. Overall, we found a self-other difference for intertemporal choice: individuals who make choices for themselves or for an intimate friend prefer later and larger (LL) rewards than those making choices for a complete stranger, thus demonstrating a 'decision maker role effect'. Secondly, regardless of chronic or induced regulatory focus, participants with a promotion focus preferred more immediate rewards, while participants with a prevention focus preferred deferred rewards. The self-other difference in intertemporal choice was manifested differently for those holding a chronic promotion focus versus those holding a chronic prevention focus; situationally induced regulatory focus, on the other hand, was found to play a mediating role in self-other intertemporal choice.
\end{abstract}

\section{Introduction}

Imagine being offered a choice between two monetary rewards: one option involves $\$ 10$ being awarded right away, while the other provides $\$ 15$ after one week. Which option would you choose? In our daily life, we are continuously confronted with choices that involve trade-offs between costs and delayed payoffs. Should you spend the money you make immediately or deposit it and spend it later? Should you take that job now, or spend more time in education in order to have a chance at a better job later on? This kind of decision making is known as intertemporal choice (Loewenstein, Read, \& Baumeister, 2004).

Given that intertemporal choice is so widespread, it has received significant attention across the fields of psychology, neuroscience and economics. A fundamental discovery is that individuals put larger value on sooner and smaller (SS) options than later and larger (LL) options, an effect known as the "time discount phenomenon", or "Immediacy Effects" (Frederick, Loewenstein, \& O'donoghue, 2002; Wang, Hao, Hu, \& Shi, 2017). Just as in the opening example, most people will prefer to get $\$ 10$ right now than obtaining \$15 in one week. That is to say, most people prefer the SS option over the LL option. However, this tendency can reverse in some situations. For example, when two rewards are both far away in time, decision makers act relatively patiently, choosing the LL option. It is only when both rewards are brought forward in time that these preferences exhibit a reversal, reflecting greater impatience (Angeletos, Laibson, Repetto, Tobacman, \& Weinberg, 2001). This is known as a Dynamic Inconsistency Effect.

To our knowledge, one aspect of intertemporal choice which has been thus far overlooked is the issue of social context. Imagine that a friend asks you whether he should retain his stocks in order to make more money, or undersell them right now. Would you make the same decision for a friend as you would for yourself? The existing research on intertemporal choice has mainly focused on making choices for oneself, and cannot be generalized to the making of decisions for others. This narrowed focus is surprising given that, in the real world, many important decisions are made on behalf of others: investment managers must make decisions for their investors, physicians make medical choices for their patients (Ubel, Angott, \& Zikmund-Fisher, 2011), attorneys negotiate for their clients, and so forth.

\footnotetext{
* Corresponding authors.

E-mail addresses: pmaguire@cs.nuim.ie (P. Maguire), 40990056@qq.com (X. Zhang), 397471731@qq.com (X. Zhang), 614096@sdnu.edu.cn (Y. Hu).

${ }^{1}$ Co-first author.
} 
The idea of a self-other difference in making such choices has been investigated in several limited contexts. For example, some studies have reported that individuals tend to be more risk-taking when making decisions on behalf of others (Beisswanger, Stone, Hupp, \& Allgaier, 2003; Hsee \& Weber, 1997; Stone, Yates, \& Caruthers, 2002; Wang, Wang, Li, \& Hu, 2018; Wray \& Stone, 2005), while others have reported the opposite, that individuals tend to be more risk-taking when making decisions for themselves (Wallach \& Wing, 1968). What is clear, despite the contradictory evidence, is that decision making differs when people decide for others compared to when people decide for themselves. We henceforth refer to this phenomenon as the "decision maker role effect".

Although self-other differences have been reported in the literature, there has been less of a focus in examining such differences in the context of intertemporal choices. The typical paradigm for studying intertemporal choice is to use the time discount rate as an indicator to evaluate individuals' level of patience when confronted with an intertemporal choice. In contrast, we use individuals' preference for the SS option as a dependent variable, following the technique used by McClure, Laibson, Loewenstein, and Cohen (2004). This way we can provide a relative measurement which can be applied to compare decisions made for the self against decisions made for others. Finally, we also bring regulatory focus theory into play, investigating the role it plays in self-other differences for intertemporal choices.

\subsection{Related research and hypotheses}

Several studies have investigated self-other differences for intertemporal choices. For example, a study by Ziegler and Tunney (2012) showed that taking the perspective of another person shifts preferences towards later, larger rewards as contrasted against maintaining one's own perspective. In another study, Albrecht, Volz, Sutter, Laibson, and Von Cramon (2010) shows that individuals are more patient when deciding for others when choosing between an immediate reward and a delayed reward. In line with these findings, Chen and He (2014) similarly found that individuals preferred the LL option than the SS option when making decisions for others. Given these results, we expected that a self-other difference appears when people need to choose one between an immediate reward and a delayed reward. Specifically, we hypothesized that an individual will be inclined to choose an LL option for others, but choose the SS option for themselves $\left(\mathrm{H}_{1}\right)$.

In an early study investigating self-other differences for risky choices, a different type-of-others condition (others in U.S., others on campus, and next person) was used to explore the nature of self-others discrepancies. The results revealed that participants predicted 'abstract' others to be more risk seeking than themselves, but did not predict vividly depicted others to be so (Hsee \& Weber, 1997). Indeed, in several more recent studies, researchers have begun to explore the effect of different others on self-other differences involving intertemporal choice. For example, Albrecht et al. (2010) asked participants to perform a time discounting task from the perspectives of close and distant others, as well as from their own perspective. They found that people tended to discount less steeply for themselves, with the steepness of time discounting increasing with distance from self. Furthermore, Ziegler and Tunney (2012) found that, when making decisions for best friends, such decisions were similar in impulsivity to those made for one's own self, while those made for unrelated strangers were less impulsive.

How can self-other differences be quantified? The idea of social distance (Trope \& Liberman, 2003) provides a useful tool. If people take the self as the point of origin (social distance is zero), then different others should arrange themselves around the self (social distance is great than zero; Trope \& Liberman, 2010; Polman, 2012a, 2012b). Previous results have indicated that self-other differences vary according to the social distance between oneself and different others. In light of this, we hypothesize that self-other differences occur when the social distance between oneself and another is large, but disappear when the social distance between oneself and another is relatively close $\left(\mathrm{H}_{2}\right)$. We observe a distinction in the class of others, namely someone close-to-self (e.g., an intimate friend) and someone distant- to-self (e.g., a complete stranger). We adopt the IOS scale (Aron, Aron, \& Smollan, 1992) to evaluate self-other social distance, aiming to ascertain whether this factor exerts a significant effect on intertemporal choices made for oneself versus those made for others.

\subsection{The role of regulatory focus}

In addition to dividing the category of 'others', we should also consider the possibility that characteristics associated with the self can also influence self-other differences in decision making, for example, regulatory focus. In general, studies on decision making tend to remain silent about how personality might affect people's perception about goals and how to pursue goals. We suggest that regulatory focus theory (Higgins, 1987) might prove valuable in capturing and quantifying such effects.

Regulatory focus can be defined both as a stable disposition and as a psychological state (Friedman \& FoRster, 2001; Wallace \& Chen, 2006). The type of focus known as chronic regulatory focus is a fixed personality tendency gradually influenced by family environment and parenting style during the process of personal development (Higgins, 1997). The other type, known as situational regulatory focus, can be primed or evoked by situational cues (Crowe \& Higgins, 1997; Lockwood, Jordan, \& Kunda, 2002). Each regulatory focus identifies two basic motivational orientations that individuals adopt in decision making, namely promotion focus and prevention focus. Individuals with a promotion focus perceive their goals as hopes and aspirations, and are sensitive to the presence or absence of positive outcomes. In contrast, individuals with a prevention focus perceive the same goals as duties and obligations, making them sensitive to the absence or presence of negative outcomes (Crowe \& Higgins, 1997; Higgins, 2000; Higgins, Shah, \& Friedman, 1997; Lockwood et al., 2002). More importantly, research has shown that both promotion attributes and prevention attributes are related to intertemporal consumption. For example, Mogilner, Aaker, and Pennington (2008) found that when consumers are confronted with immediate consumption, goods with prevention attributes are judged to be more attractive than those with promotion attributes; in contrast, when people are confronted with long-term consumption, goods with promotion attributes are preferred. In another study, Pennington and Roese (2003) explored the relationship between regulatory focus and temporal distance, concluding that immediate choices lead to a focus on prevention attributes, while long-term choices lead to a focus on promotion attributes. For example, holding a prevention focus leads people to pay greater attention to risks that they are seeking to avoid. Holding a promotion focus, on the other hand, highlights desirable outcomes. For example, given a promotion focus, a larger monetary reward in the future becomes more salient. Of special interest here is that regulatory focus can be investigated, not only from the perspective of chronic individual differences (i.e. stable personality traits), but also from the perspective of a situationally induced focus (i.e. a temporary tendency induced by situational factors; Molden, Lee, \& Higgins, 2010). Whether participants have either a chronic or an induced situational regulatory focus, we expect that those holding a prevention focus will seek to avoid future risk, and would choose the SS option, whereas those holding a promotion focus will choose the $\mathrm{LL}$ option $\left(\mathrm{H}_{3}\right)$.

One issue standing in the way of mapping out self-other intertemporal choice is that most studies have concentrated only on one of the two theories in isolation, while neglecting the interactions between them. Indeed, shifts in social distance have been shown to lead to changes in regulatory focus, suggesting that social distance and regulatory focus interact with each other (Beisswanger et al., 2003; Mogilner et al., 2008; Pennington \& Roese, 2003; Polman, 2012a, 2012b). For example, Polman (2012a, 2012b) found that decisions made for someone else induced a promotion focus, whereas decisions made for oneself triggered a prevention focus. Beisswanger et al. (2003) found that people gave more positive accounts after choosing for others, compared to those choosing for themselves, who were more sensitive to negative outcomes. In particular, Pennington and Roese (2003) found that as social distance increased, so too did promotion 
related concerns. Thus, we predict that decisions made for someone else will induce a promotion focus, whereas decisions made for oneself will trigger a prevention focus $\left(\mathrm{H}_{4}\right)$. More importantly, combining $\mathrm{H}_{3}$ with $\mathrm{H}_{4}$, we hypothesize that individuals induced with a situational promotion focus by making a decision for someone else will choose the LL option, while individuals induced with a situational prevention focus by making a decision for themselves will choose the SS option. In other words, we expect that situational regulatory focus will play a mediating role in self-other intertemporal choice $\left(\mathrm{H}_{5}\right)$.

Although both chronic and situationally-derived regulatory focus can influence decision making, the roles they play can be different. In this paper, we induce and measure the two types of regulatory focus, and carefully examine the roles they play in self-other intertemporal choice.

\section{Overview of the present study}

The current research aims to examine self-other decision making differences in the intertemporal choice context, owing to decision maker role effect, and investigate whether self-other differences vary according to different types of regulatory focus. In Study 1, participants were selected through a Regulatory Focus Questionnaire (RFQ) (Higgins et al., 2001) as demonstrating either a chronic promotion focus or a chronic prevention focus, and asked to carry out an intertemporal choice task for themselves, an intimate friend and a complete stranger respectively. In light of the possibility of situational regulatory focus being susceptible to social distance, we designed a causal chain of studies (Study 2a and 2b) to further examine the role of situational regulatory focus in self-other intertemporal choice. Decision maker role was manipulated in Study 2a, while regulatory focus type was manipulated in Study 2b. RFQ was again used to evaluate the regulatory focus type of participants in Study 2a. In Study 2b, participants were induced into either a situational promotion focus or a situational prevention focus through a written assignment about hopes/aspirations and duties/obligations (Beisswanger et al., 2003), before completing an intertemporal choice task, as per Study 1.

\subsection{Study 1}

This study aims to investigate whether self-other differences occur when participants make intertemporal choices for themselves and for others, and to investigate the role of chronic regulatory focus on selfother intertemporal choice.

\subsubsection{Method}

2.1.1.1. Participants. Seventy-five students (38 females, $M=18.73$, $S D=0.76$ ) from two universities in China were selected through RFQ to participate in this study. Four participants were deleted due to incomplete information. All participants provided written consent and were rewarded with small gifts for their participation. None were aware of the purpose of the study, or had previously been involved in a similar experiment.

2.1.1.2. Design. A 3 (decision maker role: decision for self vs decision for an intimate friend vs decision for a complete stranger) $\times 2$ (chronic regulatory focus: chronic prevention focus vs chronic promotion focus) mixed design were employed in Study 1, with chronic regulatory focus as a between-subject variable and decision maker role as a withinsubject variable. The dependent variable was the proportion of participants choosing immediate rewards.

\subsubsection{Materials and tasks}

2.1.2.1. Regulatory Focus Questionnaire. RFQ, developed by Higgins et al. (2001), was used to measure participants' chronic regulatory focus. The questionnaire consisted of 11 items, 6 measuring chronic promotion focus (e.g. "you can always finish things that you pay great effort to?") and 5 measuring chronic prevention focus (e.g. "you usually comply with the principles stipulated by your parents?"). The questionnaire used a Likert 5-point scale ranging from 1 (disagree completely) to 5 (agree completely). The Cronbach's alpha for the Promotion scale was 0.73, while that for the Prevention scale was 0.80 .

2.1.2.2. Inclusion of other in the self scale. We adopted the IOS scale developed by Aron et al. (1992), using it to measure the social distance between the self and different others. Seven double-circles with increasing degrees of overlap were used to reference a 7-point interval scale. The more the two circles overlapped, the closer the relationship between self and other they were intended to indicate. We encoded the responses such that 1 represented the relationship with a complete stranger and 7 represented a very intimate relationship, such as with a closer friend. The Cronbach's alpha for the IOS scale was 0.93.

2.1.2.3. Intertemporal choice task. We used the intertemporal choice task developed by McClure et al. (2004). Participants were required to make a series of binary choices between smaller/earlier and larger/later rewards. The early option always had a lower value than the later option. The two options were separated by delay times of either 2 weeks or 4 weeks. The immediate rewards were selected randomly from a normal distribution, and the ratios of the delayed reward to the immediate reward were $1 \%, 3 \%, 5 \%, 10 \%, 15 \%, 25 \%, 35 \%$ and $50 \%$.

2.1.2.4. Procedures. After filling out written consent and receiving an explanation of the experiment, participants were asked to complete a computerized task edited using E-prime 2.0. After entering basic personal information (including number, age and gender), they then entered the next screen, where instructions were presented describing the specific experimental process in detail. Subsequently, participants entered the exercise phase, practicing one or more times depending on their own needs. After mastering the experimental operation, participants entered the formal decision task, involving three sections. Specifically, every participant was asked to make a decision for themselves, an intimate friend and for a complete stranger respectively, with the manipulation of decision maker role randomized in order to eliminate an order effect. To measure social distance, the IOS scale was presented prior to completing the intertemporal task involving others. Participants were asked to choose one picture which best represented the relationship between themselves and their intimate friends, or a complete stranger. Finally, we thanked the participants and gave them small gifts as a reward for their participation.

\subsubsection{Results}

2.1.3.1. Manipulation checks. Thirty-five participants with an RFQ score above 1 were allocated to the chronic promotion focus group, while 40 participants with an RFQ score below -1 were allocated to the chronic prevention focus group. We conducted an independent sample $t$-test between the two groups, which showed a significant difference between them. Specifically, participants with a chronic promotion focus ( $M=22.03$ ) scored higher on the promotion focus scale than those with a chronic prevention focus $(M=15.55)$, $t_{(73)}=9.68, p<.001$. Similarly, participants with a chronic prevention focus $(M=20.05)$ scored higher on the chronic prevention focus scale than those with a chronic promotion focus ( $M=12.74), t_{(73)}=11.01, p<.001$. These results suggest that the grouping was successful and meaningful.

Next, we conducted a paired sample $t$-test on individuals' IOS scores, revealing a significant main effect, $t_{(70)}=24.76, p<.001$. Specifically, participants choosing for an intimate friend $(M=5.89)$ scored higher than those choosing for a complete stranger $(M=1.68)$, thus establishing that "intimate friend" succeeds in representing someone close to oneself, while "complete stranger" succeeds in representing someone distant to oneself.

2.1.3.2. Main findings. We conducted a 3 (decision maker role: decision for self vs decision for an intimate friend vs decision for a complete stranger) $\times 2$ (chronic regulatory focus: chronic promotion focus vs 


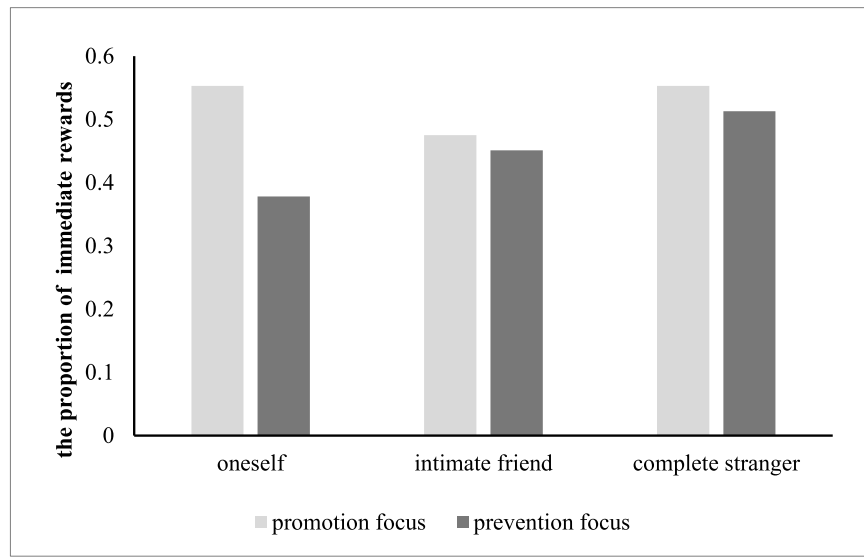

Fig. 1. Interaction effect between decision maker role and chronic regulatory focus.

chronic prevention focus) repeated measures ANOVA on the proportion of participants choosing immediate rewards. The test for homogeneity of variance was not significant. This revealed two significant main effects. Firstly, the main effect of decision maker role was significant, $F$ $(2,138)=5.29, p<.01, \eta_{\mathrm{p}}{ }^{2}=0.07$. Participants choosing for a complete stranger $(M=0.53)$ preferred more immediate rewards than those choosing for themselves $(M=0.47)$ or for an intimate friend $(M=0.46)$, while no difference was found between those choosing for themselves and for an intimate friend. On the other hand, the main effect of chronic regulatory focus was marginally significant, $F(1,69)=3.59, p=.06, \eta_{\mathrm{p}}{ }^{2}=0.05$. Participants with a chronic promotion focus $(M=0.52)$ preferred more immediate rewards compared to participants with a chronic prevention focus $(M=0.48)$. More importantly, we found the predicted significant interaction, $F(2$, $138)=5.72, p<.01, \eta_{\mathrm{p}}{ }^{2}=0.08$. Simple effect analysis showed that participants with a promotion focus showed a marginally significant self-other difference in choosing for self $(M=0.55)$, an intimate friend $(M=0.48)$ and a complete stranger $(M=0.55), F(2,14)=3.15$, $p=.05$. Participants with a prevention focus, on the other hand, preferred more immediate rewards $(M=0.51)$ when deciding for a complete stranger than for self $(M=0.38)$ or for an intimate friend $(M=0.45), F(2,138)=8.21, p<.001$.

These differences between promotion and prevention focus only exist when deciding for oneself; when deciding for friends or when deciding for strangers, the differences disappear (see Fig. 1). Specifically, participants with a chronic promotion focus $(M=0.55)$ preferred more immediate rewards compared to participants with a chronic prevention focus $(M=0.38)$ when choosing for themselves, $F(1$, $69)=10.92, p<.01$. However, when participants chose for an intimate friend, this difference was not significant between participants with a chronic prevention focus $(M=0.45)$ and those with a promotion focus $(M=0.48), F(1,69)=0.32, p=.572$. Similarly, no difference was found among individuals with a chronic promotion focus $(M=0.55)$ and a prevention focus $(M=0.51)$ when they chose for a complete stranger, $F(1,69)=0.53, p=.471$.

\subsubsection{Discussion}

In sum, this study elaborated on the nature of the relationship with others, using IOS to separate others into someone close-to-self (i.e., an intimate friend) and someone distant-to-self (i.e., a complete stranger). Of particular interest is the finding that participants choosing for someone distant to themselves preferred more immediate rewards than those choosing for themselves or someone close to themselves, thus demonstrating a decision maker role effect. Another notable finding is that participants with a chronic promotion focus prefer more immediate rewards compared to participants with a chronic prevention focus when choosing for themselves. This difference, however, vanishes when it comes to making decisions for complete strangers. Our results serve to strengthen the hypothesis that self-other differences for intertemporal choice are affected by people's chronic regulatory focus.

\subsection{Study 2}

This study was carried out to examine the influence of situational regulatory focus on self-other intertemporal choice by manipulating both the independent variable (self-other decision making role) and the situational regulatory focus. In Study 2a, participants were asked to respond to scenarios concerning choices they would make for themselves, someone close-to-self (i.e., an intimate friend) and someone distant-to-self (i.e., a complete stranger). Next, participants completed the 11-item RFQ measuring promotion and prevention focus. In Study $2 \mathrm{~b}$, participants were induced with either a promotion or a prevention focus and then asked to complete the intertemporal task. The primary dependent variables for studies $2 \mathrm{a}$ and $2 \mathrm{~b}$ were the reported levels of promotion and prevention during self-other decision making (2a), and the proportion choosing immediate rewards among promotion-focused and prevention-focused participants ( $2 \mathrm{~b}$ ). These studies aimed to clarify the relationship between self-other decision making, situational regulatory focus, and intertemporal choice.

\subsubsection{Method}

2.2.1.1. Participants. One hundred and sixty participants were recruited to take part in this experiment. Eight participants were deleted for incomplete information. In Study 2a $(N=86,53$ females, $M=20.09, S D=0.73)$, the effect of self-other decision making role on regulatory focus was investigated, while in Study $2 \mathrm{~b}(N=66,39$ females, $M=20.78, S D=0.83$ ), the effect of situational regulatory focus on intertemporal choice was investigated. All participants provided written consent and were rewarded with small gifts for their participation. None were aware of the purpose of the study, or had previously been involved in a similar experiment.

2.2.1.2. Materials and tasks. In Study 2a, we adapted 11 real-world scenarios used by Beisswanger et al. (2003). These scenarios were originally developed to examine whether people make decisions about romantic relationships differently when deciding for themselves versus for others. For example:

You and your friend are at a party. You see someone attractive across the room and

you would like to introduce yourself, but meanwhile you hesitate because you are

afraid that it may lead to you becoming separated from your group, so you decide to: 
In Study $2 \mathrm{~b}$, the intertemporal choice task was identical to that used in Study 1 with the exception that situational regulatory focus was manipulated (Friedman \& FoRster, 2001; Pham \& Avnet, 2004). A situational promotion focus was achieved by asking participants to answer several questions about their hopes and aspirations in life, job, learning and friendship, as well as what strategies they would implement to achieve these hopes and aspirations. In contrast, a situational prevention focus was achieved by asking participants to answer several questions about their duties and obligations as well as what strategies they would implement to achieve these duties and obligations (see Polman, 2012a, 2012b).

Social distance, as measured by the IOS, was the independent variable in Study 2a, while the RFQ score was the dependent variable. In Study $2 \mathrm{~b}$ the independent variable was the manipulation of situational regulatory focus, while the dependent variable was the proportion of participants choosing immediate rewards on the intertemporal choice task.

2.2.1.3. Procedures. After filling out written consent and receiving an explanation of the experiment, participants were asked to complete the task. Specifically, in Study 2a, 86 participants were first randomly assigned into three groups and asked to make a series of choices for themselves $(N=27)$, an intimate friend $(N=26)$ or a complete stranger $(N=33)$. In the two conditions involving others, we presented the IOS before participants filled out the RFQ. After that, all participants filled out the 11-item regulatory focus questionnaire measuring situational promotion focus and prevention focus.

In Study 2b, situational regulatory focus was manipulated. Specifically, 66 participants were randomly divided between a promotion focus group $(N=31)$ and a prevention focus group $(N=35)$. After answering the manipulating questions, participants were asked to complete the intertemporal choice task as per Study 1. Finally, we thanked the participants involved in the experiment and rewarded them with small gifts.

\subsubsection{Results}

We conducted an independent sample $t$-test between IOS scores for an intimate friend versus for a complete stranger which, as expected, revealed a significant difference, $t_{(57)}=-20.59, \quad p<.001$. Specifically, participants making decisions for an intimate friend $(M=6.09)$ scored higher on the IOS scale than those choosing for a complete stranger $(M=2.01)$, demonstrating that "intimate friend" was capable of representing someone close to oneself and "complete stranger" was capable of representing someone distant to oneself.

Although promotion focus was not correlated with prevention focus, we controlled for each regulatory focus separately in the analysis. For the promotion focus score, we found that the main effect of decision maker role was significant, $F(2,83)=8.57, p<.001, \eta_{\mathrm{p}}{ }^{2}=0.17$. Further post hoc testing showed that decision for a complete stranger $(M=18.73)$ was significantly different to decision for oneself $(M=17.04)$ and for an intimate friend $(M=17.85)$. However, there was no significant difference between decision for an intimate friend and decision for oneself ( $p=.510$ ) (see Fig. 2). For the prevention focus score, we also found that the main effect of decision maker role was significant, $F(2,83)=4.12, p<.05, \eta_{\mathrm{p}}{ }^{2}=0.09$. Further post hoc testing showed that decision for oneself $(M=12.70)$ and for an intimate friend ( $M=12.67)$ was significantly different to decision for a complete stranger $(M=11.24)$. No differences were found between individuals who made decisions for themselves and for an intimate friend $(p=.936)$ (see Fig. 3). The test for homogeneity of variance was not significant.

In sum, the results of Study 2a support the existence of a link between self-other decision making (decision making role) and regulatory focus type. Specifically, decision making for a complete stranger was influenced by promotion focus, whereas decision making for oneself and for an intimate friend was influenced by prevention focus.

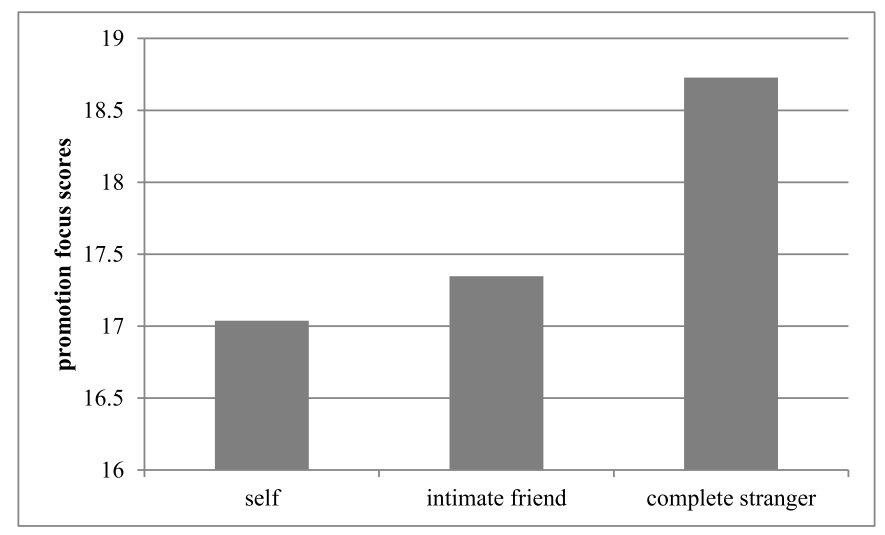

Fig. 2. Promotion focus scores for self and different others.

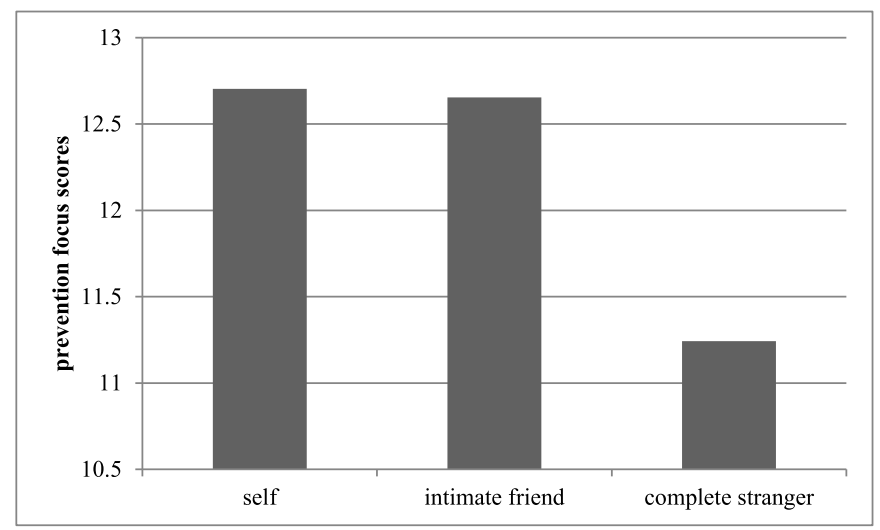

Fig. 3. Prevention focus scores for self and different others.

For Study 2b, we conducted a one-way ANOVA on intertemporal choice. This revealed a significant main effect of situational regulatory focus on intertemporal choice, $F(1,64)=9.35, p<.01, \eta_{\mathrm{p}}{ }^{2}=0.13$. The test for homogeneity of variance was not significant. In particular, participants induced with a promotion focus preferred to choose smaller and more immediate rewards $(M=0.56)$ than participants induced with a prevention focus $(M=0.40)$. These results again support the existence of a link between regulatory focus type and intertemporal choice.

\subsubsection{Discussion}

Study $2 \mathrm{a}$ and $2 \mathrm{~b}$ attest to the influence of situational regulatory focus on self-other intertemporal choice. On the one hand, the results of Study 2a support the existence of a link between self-other decision making (decision making role) and situational regulatory focus, as reported by Polman (2012a, 2012b). However, the difference between Polman's results and ours is that we discovered a functional relation between decision maker role and situational regulatory focus. Specifically, decision making for someone distant to self was related to situational promotion focus, whereas decision making for oneself and for someone close to self was related to situational prevention focus. In other words, decisions for different others induced a prevention focus or a promotion focus, and the key was the social distance between the self and different others.

The results of Study $2 \mathrm{~b}$ also support the link between regulatory focus and intertemporal choice. Specifically, individuals induced with a situational prevention regulatory focus preferred larger and later rewards, whereas individuals induced with a situational promotion focus preferred smaller and more immediate rewards. Taken together, the results of Study $2 \mathrm{a}$ and $2 \mathrm{~b}$ indicate that social distance has an important effect on situational regulatory focus (2a), which, in turn, has an 
important effect on intertemporal choice (2b). They provide evidence for the hypothesis that the effect of social distance on self-other decision making can be viewed as a linearly increasing continuum, with decision makers' behavior changing dramatically, or even reversing as distance increases.

\section{General discussion}

The current research has examined self-other decision making in an intertemporal choice context, and further broken down the effect of different types of regulatory focus on self-other intertemporal choice. Deviating from previous research, we have evaluated the social distance between self and different others using the IOS scale, dividing the concept of "different others" into someone close-to-self (e.g., an intimate friend) and someone distant-to-self (e.g., a complete stranger) according to previous research (O'Connell, Christakou, Haffey, \& Chakrabarti, 2013; Ziegler \& Tunney, 2012).

A novel discovery is that, when making intertemporal decisions for themselves (Study 1), participants preferred the LL option, while when making decisions for a complete stranger, participants preferred the SS option. This finding is inconsistent with our hypothesis $\mathrm{H}_{1}$. There are several ways of interpreting the result. Firstly, in previous research, time discount rate was used to evaluate an individual's level of patience. In contrast, we used intertemporal preference for the SS option (the proportion of participants choosing immediate rewards) as a dependent variable, which is a relative measurement. In general, individuals may place larger value on SS options than LL options. This fact, however, provides no reference point. In our study, when a reference point is provided (i.e. making a decision for someone), participants preferred the LL option when making decision for themselves, thus revealing a decision maker role effect. Another possible explanation is that, when making decisions for others, participants seek to lessen responsibility (see Leonhardt, Keller, \& Pechmann, 2011). Relative to smaller and immediate rewards, the gain of LL rewards after an extended period of time appears to be risk-seeking. Individuals may choose the SS option for others to avoid exposing them to risk.

Consistent with our hypothesis $\left(\mathrm{H}_{2}\right)$, decisions made for an intimate friend were similar to decisions for the self, but quite different to decisions made for a stranger. Research on self-other representations has demonstrated a moderating role of social distance. Specifically, people who are closer to oneself are characterized as being more similar (Aron et al., 2004; Zhou \& Su, 2008), an observation also supported by FMRI studies (Moran, Lee, \& Gabrieli, 2011). This representational similarly might explain our failure to find a significant difference between decision making for oneself and for others close to oneself in an intertemporal choice context. Another possibility is that our results can be explained in terms of cultural differences. In China, Confucian culture has such a far-reaching influence on self-concept that social distances between self and in-group members is very low, and interdependent self-construal (i.e. defining oneself in terms of relationships with others) is quite strong. For example, while Zhu and Zhang (2002) found that Chinese people have higher recall performance for events involving the self or closely related others, this finding did not replicate for Western subjects, who focused exclusively on the self.

Several findings have emerged regarding the role of regulatory focus. Firstly, regulatory focus type had a significant influence on intertemporal choice. Participants with a chronic promotion focus preferred more SS rewards compared to participants with a chronic prevention focus (Study 1). In addition, participants with an induced promotion focus preferred more SS rewards than participants with an induced prevention focus (in Study $2 b$ ). Surprisingly, these results were opposite to our hypothesis $\mathrm{H}_{3}$. That is to say, regardless of chronic or induced regulatory focus, participants with a promotion focus preferred more SS rewards, while participants with a prevention focus preferred LL rewards. Previous research has found that individuals with a promotion focus pay more attention to gains and show 'perceptual' cognition, whereas individuals with a prevention focus pay more attention to loss and show 'rational' cognition (Novak \& Hoffman, 2009; Werth \& Foerster, 2007). In line with these findings, it may be the case that, faced with SS rewards, individuals with a promotion focus interpret immediate rewards as a gain, and choose this option perceptually, whereas individuals with a prevention focus interpret SS rewards as a loss, and choose rationally to defer rewards to avoid such loss.

The second fundamental finding is that changing social distance induces different motivations when making decisions for self and different others, supporting hypothesis $\left(\mathrm{H}_{4}\right)$. Specifically, making a choice for someone distant to oneself activates a promotion focus on positive attributes, while making a choice for oneself activates a prevention focus on negative attributes. In Study 2a, we clarified this effect, observing that decision making for a complete stranger is triggered by a promotion focus, whereas decision making for oneself and for an intimate friend is triggered by a prevention focus. Of additional note is the failure to find significant differences between decisions relating to the self and decisions relating to others close to the self. We found that under conditions of close social distance and greater accountability, a prevention focus was activated, resulting in non-significant differences between self and others close-to-self. These findings are also consistent with other research, such as Lee, Aaker, and Gardner's (2000) observation that low social distance is associated with a prevention focus, and Crowe and Higgins' (1997) observation that accountability is also associated with a prevention focus.

Thirdly, chronic regulatory focus, which is stable and unsusceptible to decision maker role, had a significant influence on self-other intertemporal choice (Study 1). Specifically, we found a self-other difference for participants with a prevention focus. Such individuals preferred more immediate rewards as the social distance increased. However, this result disappeared for participants with a promotion focus. In other words, self-other difference in intertemporal choice varies between chronic prevention focus and chronic promotion focus. While these differences between promotion and prevention focus were significant when participants made decisions for themselves, they disappeared when participants made decisions for intimate friends or for complete strangers.

In contrast, situational regulatory focus can be induced. We found that choosing for someone distant to oneself (e.g., a complete stranger) induced a situational promotion focus, whereas choosing for oneself and for someone close to oneself (e.g., an intimate friend) induced a situational prevention focus (Study 2a). Similarly, we found that changes in situational regulatory focus further influenced individuals' intertemporal behavior (Study 2b). Individuals with an induced promotion focus preferred SS rewards, while individuals with an induced prevention focus preferred LL rewards. Taken together, these two supportive results for hypothesis $\left(\mathrm{H}_{5}\right)$ reveal that situational regulatory focus plays a mediating role between decision maker role and intertemporal choice.

In sum, the current study has investigated the relationship between intertemporal choice, self-other decision making, and regulatory focus types, contributing in three different ways to the current state of knowledge. Most of the existing research in this area has focused on intertemporal choices for oneself, paying less attention to decisions made for others. Our results show clearly that when individuals are faced with the same situation at the same time, they prefer the SS rewards for someone distant to themselves, but prefer LL rewards for themselves and for those closer to themselves, revealing a decision maker role effect occur for intertemporal choice contexts. In particular, regulatory focus theory can be used to explain the mechanisms behind this effect. The theoretical implications of the present work reach beyond and broaden the existing research on intertemporal choice behavior.

A second novel contribution of our work is that it further clarifies the nature of social distance between the self and different others. Previous studies on self-other differences in decision making have 
tended to define social distance by distinguishing between specific (e.g., friend) and abstract categories of others (e.g., typical students). Although most of these studies have shown that deciding for someone else is different from deciding for oneself (Beisswanger et al., 2003; Hibbing \& Alford, 2005; Hsee \& Weber, 1997; Stone et al., 2002), relatively few studies have reported differences between different categories of others. Based on a definition of social distance developed within social psychology, we subdivided different others by evaluating their social distances using the IOS scale. Our results suggest that social distance can be represented on a continuum, with self as the origin, insofar as results for close-to-self others resemble those based on the self, whereas results for distantly related others bear less resemblance.

Finally, our work demonstrates that, when it comes to intertemporal choice behavior, the social distance hypothesis and regulatory focus theory are connected (Mogilner et al., 2008; Pennington \& Roese, 2003). For example, when making a choice for oneself or for an intimate friend, a prevention focus is activated, whereas when making a choice for a complete stranger a promotion focus is activated. The application of regulatory focus to self-other decision making manages to reconcile the social distance hypothesis and regulatory focus theory into a single unifying theory.

\section{Limitations and future research}

Although this research has provided valuable insight into self-other intertemporal choice, there are some limitations to keep in mind. The first limitation is that the intertemporal task in our experiment only involved choice in a gain frame. Other studies have shown an asymmetry phenomenon between gain and loss frames. For instance, in the field of risk decision making, which is similar to intertemporal choice (Prelec \& Loewenstein, 1991), individuals have been shown to be more risk-seeking under the loss frame then the gain frame (Hsee \& Weber, 1997; Kahneman \& Tversky, 1979; Levin, Schneider, \& Gaeth, 1998). What's more, Kwan, John, Kenny, Bond, and Robins (2004) found that, under a gain frame, decisions made for oneself tended to be more riskseeking than the predicted decisions made by other people; under a loss frame, the opposite was found. As explained by the self-promotion hypothesis, people tend to believe that others pay more attention to gains or losses in different frames. They believe that, compared with themselves, others prefer a handy small gain rather than being willing to take a risk for a larger gain. This effect is reversed under a loss frame. Given that most decisions we face in real life consist of potential gains as well as potential losses, it may be worthwhile for a future study to examine the interaction of decision makers' role and task frame for intertemporal choice.

The second limitation is that our intertemporal choices only included immediate rewards and delayed (two weeks or four weeks) rewards. Previous studies have found many reasoning anomalies, such as dynamic inconsistency effects (Angeletos et al., 2001), magnitude effects (Benzion, Rapoport, \& Yagil, 1989), sign effects (Thaler, 1981), sequence effects (Frederick et al., 2002) and so on. Taking dynamic inconsistency effects for example, when individuals confront immediate and delayed rewards, they tend to prefer the immediate one because the delayed rewards are devalued compared to the immediate rewards. In contrast, when individuals confront two delayed options, the preference reverses. An interesting avenue for future research would be to explore whether these psychological anomalies also appear when people make choices for others, as opposed to themselves.

A final limitation of these studies concerns the lack of diversity among participants, all of whom were university students in China. In order to support greater generalizability, future studies should aim to recruit participants from a more diverse set of backgrounds.

\section{Conclusion}

In conclusion, our findings demonstrate a clear self-other discrepancy in the context of intertemporal choice. Individuals who choose for themselves and for an intimate friend have a greater preference for LL rewards than those who choose for a complete stranger, thus demonstrating a decision maker role effect. Interestingly, there are no such differences between deciding for oneself and deciding for an intimate friend. As we have seen, regulatory focus exerts an important influence on intertemporal choice. Regardless of being chronic or situationally induced, decision making for a complete stranger is related to promotion focus, whereas decision making for oneself and for an intimate friend is related to prevention focus. Specifically, chronic regulatory focus affects how the difference in self-other intertemporal choice is manifested, while situational regulatory focus plays a mediating role in self-other intertemporal choice.

\section{Ethical approval}

All procedures performed in studies involving human participants were in accordance with the ethical standards of the Academic Board of Shandong Normal University and with the 1964 Helsinki declaration and its later amendments or comparable ethical standards.

\section{Informed consent}

Informed consent was obtained from all individual participants included in the study.

\section{Declaration of Competing Interest}

The authors declare that they have no conflict of interest.

\section{Acknowledgement}

National Natural Science Fund of China, grant/award number: 31471002; The Graduate Enterprise Program of China, grant/award numbers: 201610445184, 201710445187; Natural Science Foundation of Shandong Province, grant/award number: ZR2014CM033; Key Research and Development Program in Shandong Province, grant/ award number: 2015GSF120015; Domestic Visiting Scholar Program of Shandong Normal University, grant/award number: SDVUDVS 2018; Key technology projects of Shengli Oilfield Administration China, grant/award number: GKS1701; Young People of Humanities and Social Sciences of the Ministry of Education of China, grant/award number: 15YJC190006.

\section{References}

Albrecht, K., Volz, K. G., Sutter, M., Laibson, D. I., \& Von Cramon, D. Y. (2010). What is for me is not for you: Brain correlates of intertemporal choice for self and other. Social Cognitive and Affective Neuroscience, 6(2), 218-225.

Angeletos, G., Laibson, D., Repetto, A., Tobacman, J., \& Weinberg, S. (2001). The hyperbolic consumption model: Calibration, simulation, and empirical evaluation. Journal of Economic Perspectives, 15(3), 47-68.

Aron, A., Aron, E. N., \& Smollan, D. (1992). Inclusion of other in the self scale and the structure of interpersonal closeness. Journal of Personality and Social Psychology, 63(4), 596-612.

Beisswanger, A. H., Stone, E. R., Hupp, J. M., \& Allgaier, L. (2003). Risk taking in relationships: Differences in deciding for oneself versus for a friend. Basic and Applied Social Psychology, 25, 121-135.

Benzion, U., Rapoport, A., \& Yagil, J. (1989). Discount rate inferred from decision: An experiment study. Management Science, 35(3), 270-284.

Chen, H. X., \& He, G. B. (2014). The effect of psychological distance on intertemporal choice and risky choice. Acta Psychologica Sinica, 46(5), 677-690.

Crowe, E., \& Higgins, E. T. (1997). Regulatory focus and strategic inclinations: Promotion and prevention in decision-making. Organizational Behavior and Human Decision Processes, 69, 117-132.

Frederick, S., Loewenstein, G., \& O'donoghue, T. (2002). Time discounting and time preference: A critical review. Journal of Economic Literature, 40(2), 351-401.

Friedman, R. S., \& FoRster, J. (2001). The effects of promotion and prevention cues on creativity. Journal of Personality and Social Psychology, 81(6), 1001-1013.

Hibbing, J. R., \& Alford, J. R. (2005). Decision making on behalf of others. Paper presented at the annual meeting of the American Political Science Association, Washington, DC. 
Higgins, E. T. (1987). Self-discrepancy: A theory relating self and affect. Psychological Review, 94(3), 319.

Higgins, E. T. (2000). Making a good decision: Value from fit. American Psychologist, 55, $1217-1230$

Higgins, E. T. (1997). Beyond pleasure and pain. American Psychologist, 52, 1280-1300.

Higgins, E. T., Friedman, R. S., Harlow, R. E., Idson, L. C., Ayduk, O. N., \& Taylor, A. (2001). Achievement orientations from subjective histories of success: Promotion pride versus prevention pride. European Journal of Social Psychology, 31, 3-23.

Higgins, E. T., Shah, J., \& Friedman, R. (1997). Emotional responses to goal attainment: Strength of regulatory focus as moderator. Journal of Personality and Social Psychology, 72(3), 515-525.

Hsee, K. C., \& Weber, U. E. (1997). A fundamental prediction error: Self-others discrepancies in risk preference. Journal of Experimental Psychology: General, 126(1), 45-53.

Kahneman, D., \& Tversky, A. (1979). Prospect theory: An analysis of decision under risk. Econometrica, 47(2), 263-291.

Kwan, V. S. Y., John, O. P., Kenny, D. A., Bond, M. H., \& Robins, R. W. (2004). Reconceptualizing individual differences in self-enhancement bias: An interpersonal approach. Psychological Review, 111, 94-111.

Lee, A. Y., Aaker, J. L., \& Gardner, W. L. (2000). The pleasures and pains of distinct selfconstruals: The role of interdependence in regulatory focus. Journal of Personality and Social Psychology, 78, 1122-1134.

Leonhardt, J. M., Keller, L. R., \& Pechmann, C. (2011). Avoiding the risk of responsibility by seeking uncertainty: Responsibility aversion and preference for indirect agency when choosing for others. Journal of Consumer Psychology, 21(4), 405-413.

Levin, I. P., Schneider, S. L., \& Gaeth, G. J. (1998). All frames are not created equal: A typology and critical analysis of framing effects. Organizational Behavior and Human Decision Processes, 76(2), 149-188.

Lockwood, P., Jordan, C. H., \& Kunda, Z. (2002). Motivation by positive or negative role models: Regulatory focus determines who will best inspire us. Journal of Personality and Social Psychology, 83(4), 854.

Loewenstein, G., Read, D., \& Baumeister, R. (2004). Time and decision: Economic and psychological perspectives on intertemporal choice. Journal of Economic Literature, 64(3), 419-422.

McClure, S. M., Laibson, D. I., Loewenstein, G., \& Cohen, J. D. (2004). Separate neural systems value immediate and delayed monetary rewards. Science, 306(5685), 503-507.

Mogilner, C., Aaker, J. L., \& Pennington, G. L. (2008). Time will tell: The distant appeal of promotion and imminent appeal of prevention. Journal of Consumer Research, 34 670-681.

Molden, D. C., Lee, A. Y., \& Higgins, E. T. (2010). Motivations for promotion and prevention. Handbook of motivation science.

Moran, J. M., Lee, S. M., \& Gabrieli, J. D. E. (2011). Dissociable neural systems supporting knowledge about human character and appearance in ourselves and others. Journal of Cognitive Neuroscience, 23(9), 2222-2230.

Novak, T. P., \& Hoffman, D. L. (2009). The fit of thinking style and situation: New measures of situation-specific experiential and rational cognition. Journal of Consumer Research, 36(1), 56-72.
O'Connell, G., Christakou, A., Haffey, A. T., \& Chakrabarti, B. (2013). The role of empathy in choosing rewards from another's perspective. Frontiers in Human Neuroscience, 7, 174-179.

Pennington, G. L., \& Roese, N. J. (2003). Regulatory focus and temporal distance. Journal of Experimental Social Psychology, 39(6), 563-576.

Pham, M., \& Avnet, T. (2004). Ideals and oughts and the reliance on affect versus substance in persuasion. Journal of Consumer Research, 30(4), 503-518.

Polman, E. (2012a). Effects of self-other decision making on regulatory focus and choice overload. Journal of Personality and Social Psychology, 102(5), 980-993.

Polman, E. (2012b). Self-other decision making and loss aversion. Organizational Behavior and Human Decision Processes, 119(2), 141-150.

Prelec, D., \& Loewenstein, G. (1991). Decision making over time and under uncertainty: A common approach. Management Science, 37, 770-786.

Stone, E. R., Yates, A., \& Caruthers, A. S. (2002). Risk taking in decision making for others versus the self. Journal of Applied Social Psychology, 32, 1797-1824.

Thaler, R. (1981). Some empirical evidence of dynamic inconsistency. Economics Letters, 8(3), 201-207.

Trope, Y., \& Liberman, N. (2003). Temporal construal. Psychological Review, 110, 403-421.

Trope, Y., \& Liberman, N. (2010). Construal level theory of psychological distance. Psychological Review, 117, 440-463.

Ubel, P. A., Angott, A. M., \& Zikmund-Fisher, B. J. (2011). Physicians recommend dif ferent treatments for patients than they would choose for themselves. Archives of Internal Medicine, 171, 630-634.

Wallace, C., \& Chen, G. (2006). A multilevel integration of personality, climate, selfregulation, and performance. Personnel Psychology, 59(3), 529-557.

Wallach, M. A., \& Wing, C. W. (1968). Is risk a value? Journal of Personality and Social Psychology, 9, 101-106.

Wang, D. W., Hao, L. L., Hu, Y. X., \& Shi, K. (2017). The underlying mechanism of intertemporal choice: Temporal discounting model or probability dynamic model. Journal of Shandong Normal University (Humanities and Social Sciences), 62(3), $117-126$.

Wang, D. W., Wang, S. Y., Li, J. R., \& Hu, Y. X. (2018). The information processing process of crisis decision-making for self and others: Evidence from eye movement. Journal of Psychological Science, 41(3), 633-638.

Werth, L., \& Foerster, J. (2007). How regulatory focus influences consumer behavior. European Journal of Social Psychology, 37(1), 33-51.

Wray, L. D., \& Stone, E. R. (2005). The role of self-esteem and anxiety in decision making for self versus others in relationships. Journal of Behavioral Decision Making, 18, 125-144.

Zhou, L., \& Su, Y. J. (2008). The role of genuine intimacy in the lover-reference effect. Acta Psychologica Sinica, 40(4), 487-495.

Zhu, Y., \& Zhang, L. (2002). An experimental study on the self-reference effect. Science China (Life Sciences), 45(2), 120-128.

Ziegler, F. V., \& Tunney, R. J. (2012). Decisions for others become less impulsive the further away they are on the family tree. PLoS One, 7(11), e49479. https://doi.org/ 10.1371/journal.pone.0049479. 